\title{
Cytotoxicity of cis-Platinum(II) Conjugate Models. The Effect of Chelating Arms and Leaving Groups on Cytotoxicity: A Quantitative Structure-Activity Relationship Approach
}

\author{
Elena Monti, ${ }^{\dagger}$ Marzia Gariboldi, ${ }^{\dagger}$ Alessandro Maiocchi, ${ }^{\ddagger}$ Emilio Marengo, ${ }^{\S}$ Claudio Cassino, $§$ \\ Elisabetta Gabano, ${ }^{\S}$ and Domenico Osella*,§ \\ Dipartimento di Biologia Strutturale e Funzionale, Università dell'Insubria, Via A. da Giussano 10, \\ 21052 Busto Arsizio (VA), Italy, Bracco Imaging, Via E. Folli 50, 20134 Milano, Italy, and Dipartimento di Scienze \\ dell'Ambiente e della Vita, Università del Piemonte Orientale "A. Avogadro", Spalto Marengo 33, 15100 Alessandria, Italy
}

Received June 22, 2004

Thirteen newly synthesized or resynthesized diamine-platinum(II) complexes were characterized, and their cytotoxic activities $\left(\mathrm{IC}_{50}\right)$ were tested on parental and resistant ovarian cancer cell lines. They represent models of conjugates between biologically active vectors and cytotoxic $\mathrm{Pt}^{\mathrm{II}}$ moieties within the "drug targeting and delivery strategy". Three drugs, routinely employed in the clinical treatment of cancer, namely, cisplatin, carboplatin, and oxaliplatin, were also included in the study as controls. The quantitative structure-activity relationship approach provides simple regression models able to predict $\log \left(1 / \mathrm{IC}_{50}\right)$ of diamine-platinum(II) complexes on both parental and resistant ovarian cancer cell lines. The 16 complexes were characterized using 197 molecular descriptors, after which the best regression models relating a subset of these descriptors to the $\log \left(1 / \mathrm{IC}_{50}\right)$ in the two cancer cell lines were calculated. Models with four variables proved to be endowed with very good predictive ability $Q^{2}$ LMO-50\% $\geq 85.6 \%$, making it possible to discard $50 \%$ of the molecules from the test set following for cross-validation procedure. A four-variable regression model also proved effective in predicting the resistance index RI, $Q^{2}{ }_{\mathrm{LMO}-50 \%}=84.4 \%$.

\section{Introduction}

Cisplatin and its second-generation analogues, carboplatin and oxaliplatin, provide good results in the treatment of solid tumors, especially in testicular, ovarian, and colon cancer (oxaliplatin only). The effectiveness of their clinical use, however, is hampered by their poor ability to select between malignant and normal cells (resulting in severe side effects) and their tendency to provoke chemoresistance.

"Drug targeting and delivery" methods in anticancer chemotherapy rely on agents with selective access to tumors to deliver drugs to the target. Approaches to finding such agents often depend on novel design strategies employing bioactive vectors, such as intercalators, amino acids, sugars, bile acids, folates, and estrogen analogues. ${ }^{1-5}$ In this last case, the rationale is that estrogen-specific receptor proteins are expressed at higher levels in a significant fraction of breast carcinomas $(\mathrm{ER}+)$ than those in normal breast tissue. ${ }^{6-9}$ Thus, anchoring $\mathrm{Pt}^{\mathrm{II}}$ derivatives to estrogen moieties could yield a family of anticancer drugs with preferential access to breast cancer cell nuclei, allowing for significant improvement in the therapeutic index. A similar approach is to label estrogen derivatives with $\gamma$-emitting 99m Tc-derivatives for use in SPECT. ${ }^{10}$

An alternative approach takes advantage of the enhanced permeability of tumor blood vessels and the

* Author to whom correspondence should be addressed. Phone: +39-0131-287429. Fax: +39-0131-287416. E-mail: domenico.osella@ mfn.unipmn.it.

$\dagger$ Università dell'Insubria.

¥ Bracco Imaging.

$\S$ Università del Piemonte Orientale "A. Avogadro". inefficient lymphatic drainage in tumors. Macromolecular diffusion out of blood vessels is facilitated in the tumor region, so any drug delivered by an agent can accumulate in the tumor and persist for long periods of time. This phenomenon is known as the "enhanced permeability and retention" (EPR) effect. ${ }^{11-13}$

For this purpose, a coordinating arm linking the $\mathrm{Pt}$ unit to the bioactive or macromolecular carrier is required (Figure 1a). In general, a suitable arm consists of a spacer that ends in, or contains, a chelating diamine functionality (e.g., ethylenediamine or piperazine). In both the cases, the spacer should preferentially hydrolyze at the somewhat lower $\mathrm{pH}$ values ${ }^{14-17}$ typical of tumor tissue, thus releasing the cytotoxic agent. The vector can be linked to the arm using one of several available reactions, all of which require protection of the $\mathrm{NH}_{2}$ groups (e.g., with di-tert-butyl dicarbonate, t-BOC). The procedure involves multistep reactions, generally affording low yields. Thus, the use of tertiary amines is often preferred because it does not require protection/ deprotection steps. Furthermore, to increase solubility in water, dicarboxylate anions are often employed instead of chlorides as leaving groups. However, Cleare and Hoeschele's empirical rules ${ }^{18,19}$ remind us that substitution of the hydrogen atom in the amine carrier groups, as well as the replacement of chlorides with carboxylates as leaving groups, significantly decreases the cytotoxicity of the active cis-PtII moiety.

To achieve a more rigorously quantitative approach, we report on the biological behavior of 16 model cis- $\mathrm{Pt}{ }^{\mathrm{II}}$ complexes in which both the carrier and the leaving groups have been varied. Cytotoxicity data obtained on 
a

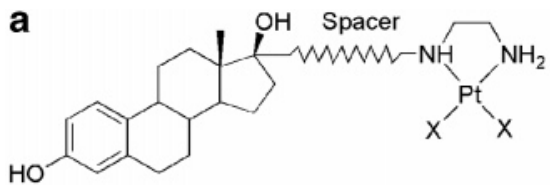

Estradiol carrier

Cytotoxic fragment

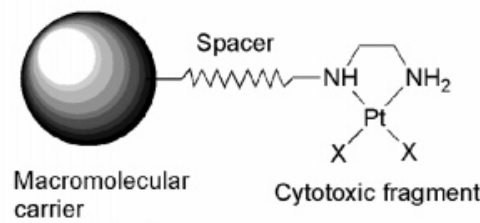

(nanosphere)

b $\quad\left[\mathrm{X}=\right.$ chloride $; \mathrm{X}_{2}=$ dicarboxylate $]$

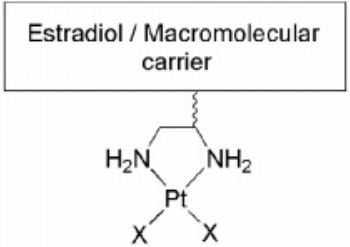

Figure 1. Bioactive and macromolecular carriers for the $\mathrm{Pt}^{\mathrm{II}}$ cytotoxic fragment.

cultured human ovarian cancer cell lines, namely, A2780 (parental cell line) and A2780Cp8 (a cisplatin resistant subline obtained by continuous in vitro exposure to increasing concentrations of the drug), ${ }^{20}$ were examined for potential quantitative structure-activity relationships (QSARs). To the best of our knowledge, although several QSAR analyses of antitumor organic agents have been reported, ${ }^{21-24}$ none concerning the cytotoxicity of platinum complexes has yet been published. The goal of this investigation is to understand, by using an in vitro model (cultured cells), whether and how the modification of the prototypal cisplatin molecule with chelating diamines (useful to link bioactive vectors) or dicarboxylates (useful to increase water solubility) is detrimental to the overall cytotoxicity.

\section{Results and Discussion}

Chemistry. We used standard procedures to newly synthesize or resynthesize 13 platinum(II) complexes with different combinations of carrier and leaving ligands. The carriers were $\mathrm{NH}_{3}$, ethylenediamine (en), $N, N, N^{\prime}, N^{\prime}$-tetramethylethylenediamine (tmen), $N, N^{\prime}$ dimethylpiperazine (dmppz), and ( $1 R, 2 R)$-1,2-diaminocyclohexane $(\mathrm{DACH})$, and the leaving ligands were chloride, propanedioato or malonato (mal), 1,1'-cyclobutanedicarboxylato (CBDC), ethanedioato or oxalato (ox); see Table 1 and Figure 2.

The compounds were synthesized according to a procedure based on Dhara's method, ${ }^{25-30}$ i.e., by reacting $\mathrm{K}_{2}\left[\mathrm{PtCl}_{4}\right]$ with $\mathrm{KI}$ to produce $\mathrm{K}_{2}\left[\mathrm{PtI}_{4}\right]$ in solution; the latter complex reacts with amines to produce the cis$\left[\mathrm{Pt}\right.$ (amine) $\left.\mathrm{I}_{2}\right]$ precipitate. This is a good synthon for obtaining the corresponding chloride or carboxylato complex. In fact, upon reaction with $\mathrm{Ag}_{2} \mathrm{SO}_{4}$ or $\mathrm{AgNO}_{3}$, cis-[Pt(amine $\left.\mathrm{I}_{2}\right]$ produces the corresponding diaqua complex, which reacts with chloride or dicarboxylalate to yield the final complex.

All of the complexes were examined using ESI-MS, multinuclear $\left({ }^{1} \mathrm{H},{ }^{13} \mathrm{C},{ }^{195} \mathrm{Pt}\right) \mathrm{NMR}$ spectroscopy, and Raman spectroscopy. The molecular formula of each compound was verified by means of the correct isotope distribution of the quasi-molecular ion peak. ESI-MS spectra of carboxylato complexes, dissolved in water/ methanol (1:1 v/v), showed the quasi-molecular ion peak $[\mathrm{M}+\mathrm{H}]^{+}$; dichloride complexes dissolved in water/ dimethylsulfoxide $(1: 1 \mathrm{v} / \mathrm{v})$ were characterized instead by the main signal attributable to the $[\mathrm{M}-\mathrm{Cl}+$ $\mathrm{DMSO}^{+}$species.

Reverse phase HPLC was employed to evaluate the purity of the compounds ( $\geq 95 \%)$.

The ${ }^{1} \mathrm{H}$ and ${ }^{13} \mathrm{C}$ NMR resonances in the complexes appared in a lower field than that of the corresponding free ligands, with the atoms closer to the $\mathrm{Pt}$ center usually more strongly affected. ${ }^{27}$ The methylene protons of the malonato ligand were not observed in the ${ }^{1} \mathrm{H}$ NMR spectra in $\mathrm{D}_{2} \mathrm{O}$ because of the rapid exchange with the deuterated solvent. This exchange also occurred when pure malonic acid was dissolved in $\mathrm{D}_{2} \mathrm{O}$. The complexation of malonate to $\mathrm{Pt}^{\mathrm{II}}$ further activates $\mathrm{H} / \mathrm{D}$ exchange. ${ }^{31}$ Interestingly, the free malonic acid ${ }^{13} \mathrm{C}$ spectrum did show the signal of the $-\mathrm{CD}_{2}-$ moiety (a quintuplet, $\delta=40.74 \mathrm{ppm},{ }^{1} J_{\mathrm{CD}}=20 \mathrm{~Hz}$ ) under basic conditions.

The identity of the products was confirmed by ${ }^{195} \mathrm{Pt}$ NMR spectroscopy. The spectra of cis- $\mathrm{PtA}_{2} \mathrm{X}_{2}(\mathrm{~A}=$ amine, $\mathrm{X}_{2}=$ dicarboxylato) complexes were recorded in

Table 1. Tested $\mathrm{Pt}^{\mathrm{II}}$ Complexes

\begin{tabular}{|c|c|}
\hline complexes & no. \\
\hline cis-diamminedichlorideplatinum(II) (cisplatin) & 1 \\
\hline cis-diamminemalonatoplatinum(II) & 2 \\
\hline cis-diammine(1,1'-cyclobutanedicarboxylato)platinum(II) (carboplatin) & 3 \\
\hline cis-dichlorideethylenediamineplatinum(II) & 4 \\
\hline cis-ethylenediaminemalonatoplatinum(II) & $\mathbf{5}$ \\
\hline cis-(1,1'-cyclobutanedicarboxylato)ethylenediamineplatinum(II) & 6 \\
\hline cis-dichloride( $N, N, N^{\prime}, N^{\prime}$-tetramethylethylenediamine)platinum(II) & 7 \\
\hline cis-malonato( $N, N, N^{\prime}, N^{\prime}$-tetramethylethylenediamine)platinum(II) & 8 \\
\hline cis-(1,1'-cyclobutanedicarboxylato $)\left(N, N, N^{\prime}, N^{\prime}\right.$-tetramethylethylenediamine)platinum(II) & $\mathbf{9}$ \\
\hline cis-dichloride( $N, N^{\prime}$-dimethylpiperazine)platinum(II) & 10 \\
\hline cis-(N,N'-dimethylpiperazine)malonatoplatinum(II) & 11 \\
\hline cis-(1,1'-cyclobutanedicarboxylato)( $N, N^{\prime}$-dimethylpiperazine)platinum(II) & 12 \\
\hline cis-dichloride $[(1 R, 2 R)$-1,2-diaminocyclohexane]platinum(II) & 13 \\
\hline cis-[(1R,2R)-1,2-diaminocyclohexane]oxalatoplatinum(II) (oxaliplatin) & 14 \\
\hline cis-[(1R,2R)-1,2-diaminocyclohexane]malonatoplatinum(II) & 15 \\
\hline cis-(1,1'-cyclobutanedicarboxylato) $[(1 R, 2 R)$-1,2-diaminocyclohexane]platinum(II) & 16 \\
\hline
\end{tabular}


<smiles>N[Pb](N)(Cl)Cl</smiles>

1<smiles>N[Pb]1(N)OC(=O)CC(=O)O1</smiles>

2<smiles>N[P+]1(N)OC(=O)C2(CCC2)C(=O)O1</smiles>

3<smiles>Cl[PH]1(Cl)N[C@H]2CCCC[C@H]2N1</smiles>

13<smiles>Cl[PH]1(Cl)NCCN1</smiles>

4<smiles>O=C1CC(=O)O[Pb]2(NCCN2)O1</smiles>

5<smiles>O=C1O[Pb]2(NCCN2)OC(=O)C12CCC2</smiles>

6<smiles>O=C1O[Pb]2(N[C@H]3CCCC[C@H]3N2)OC1=O</smiles>

14<smiles>C[N+]1(C)CC[N+](C)(C)[P]1(Cl)Cl</smiles>

7<smiles>C[N+]1(C)CC[N+](C)(C)[P]12OC(=O)CC(=O)O2</smiles>

8<smiles></smiles>

9<smiles>O=C1CC(=O)O[Pb]2(N1)N[C@@H]1CCCC[C@H]1N2</smiles>

15<smiles>CN1CCN(C)P1(Cl)(Cl)Cl</smiles>

10<smiles>CN1CCN(C)[PH]12OC(=O)CC(=O)O2</smiles>

11<smiles>CN1CCN2CCN(C)[P+]12OC(=O)C1(C(=O)O)CCC1</smiles>

12

Figure 2. Sketch of structures of the complexes.

$\mathrm{D}_{2} \mathrm{O}$ and displayed signals between -1700 and -2000 ppm as expected. ${ }^{27}$ The cis- $\mathrm{PtA}_{2} \mathrm{Cl}_{2}$ complexes were dissolved in DMSO- $d_{6}$ and exhibited signals between -2000 and $-2400 \mathrm{ppm}$ as previously reported for similar compounds. ${ }^{32,33}$

Raman spectroscopy was employed to further characterize the platinum coordination sphere. As reported in the literature, ${ }^{34-39} \mathrm{Pt}-\mathrm{N}$ stretching was seen from 600 to $400 \mathrm{~cm}^{-1}$, whereas $\mathrm{Pt}-\mathrm{Cl}$ stretching was observed near $350-300 \mathrm{~cm}^{-1}$. $\mathrm{Pt}-\mathrm{O}$ stretching (500-400 $\mathrm{cm}^{-1}$ ) and $\mathrm{O}-\mathrm{Pt}-\mathrm{O}, \mathrm{N}-\mathrm{Pt}-\mathrm{N}$, and $\mathrm{Cl}-\mathrm{Pt}-\mathrm{Cl}$ bending $\left(\leq 250 \mathrm{~cm}^{-1}\right)$ were not assigned because they are very weak and difficult to identify.

Cytotoxicity Assays. The cytotoxic properties of all of the complexes under investigation were evaluated on the A2780 human ovarian adenocarcinoma cell line and on its cisplatin-resistant subline (A2780Cp8). The mechanisms underlying tumor resistance to cisplatin are known to be multifactorial and include decreased drug transport, increased cellular detoxification due to glutathione and metallothioneins, and changes in DNA repair involving increased nucleotide excision repair (NER) and loss of mismatch repair (MMR), as well as alterations in apoptotic cell death pathways; ${ }^{20}$ in A2780Cp8 cells, multiple mechanisms were indeed found to contribute to resistant phenotype. ${ }^{40}$

Cytotoxicity tests were performed using the MTT assay, following exposure of the cells to $\mathrm{Pt}$ derivatives for $120 \mathrm{~h}$. The clinically used cisplatin (1), carboplatin (3), and oxaliplatin (14) were also included in the study as controls. In all cases, exposure to drug concentrations
Table 2. $\mathrm{IC}_{50}$ Values for the Tested Compounds

\begin{tabular}{cccr}
\hline & \multicolumn{2}{c}{$\mathrm{IC}_{50}(\mu \mathrm{M}) \mathrm{m} \pm \mathrm{SE}^{a}$} & \\
\cline { 2 - 3 } complex & \multicolumn{1}{c}{$\mathrm{A} 2780$} & $\mathrm{~A} 2780 \mathrm{Cp} 8$ & $\mathrm{RI}^{b}$ \\
\hline $\mathbf{1}$ & $1.37 \pm 0.48$ & $45.03 \pm 8.76$ & 32.9 \\
$\mathbf{2}$ & $7.32 \pm 0.39$ & $27.93 \pm 4.09$ & 3.8 \\
$\mathbf{3}$ & $7.66 \pm 0.72$ & $123.27 \pm 2.04$ & 16.1 \\
$\mathbf{4}$ & $5.55 \pm 1.17$ & $117.96 \pm 12.20$ & 21.2 \\
$\mathbf{5}$ & $8.84 \pm 2.16$ & $64.84 \pm 5.25$ & 7.3 \\
$\mathbf{6}$ & $9.21 \pm 1.03$ & $65.99 \pm 6.80$ & 7.2 \\
$\mathbf{7}$ & $27.24 \pm 1.74$ & $126.80 \pm 10.08$ & 4.6 \\
$\mathbf{8}$ & $176.03 \pm 8.23$ & $952.20 \pm 108.30$ & 5.4 \\
$\mathbf{9}$ & $135.90 \pm 8.07$ & $643.85 \pm 67.98$ & 4.7 \\
$\mathbf{1 0}$ & $38.86 \pm 8.40$ & $100.22 \pm 12.99$ & 2.6 \\
$\mathbf{1 1}$ & $167.36 \pm 27.13$ & $385.98 \pm 25.45$ & 2.3 \\
$\mathbf{1 2}$ & $167.52 \pm 31.57$ & $615.16 \pm 23.31$ & 3.7 \\
$\mathbf{1 3}$ & $1.03 \pm 0.22$ & $8.26 \pm 1.79$ & 8.0 \\
$\mathbf{1 4}$ & $0.48 \pm 0.16$ & $6.62 \pm 0.51$ & 12.4 \\
$\mathbf{1 5}$ & $2.22 \pm 0.42$ & $9.69 \pm 1.78$ & 4.4 \\
$\mathbf{1 6}$ & $1.52 \pm 0.11$ & $3.74 \pm 0.48$ & 2.5 \\
\hline
\end{tabular}

${ }^{a}$ Complex concentrations inhibiting tumor cell growth by $50 \%$. $\mathrm{IC}_{50}$ value are reported as means of three independent replication $\pm \mathrm{SE}$ (standard error). ${ }^{b}$ Resistance index $\mathrm{RI}=\left(\mathrm{IC}_{50} \mathrm{~A} 2780 \mathrm{Cp} 8\right) /$ ( $\left.\mathrm{IC}_{50} \mathrm{~A} 2780\right)$.

ranging between 0 and $500 \mu \mathrm{M}$ resulted in a dosedependent inhibition of cell survival. Table 2 shows the $\mathrm{IC}_{50}$ values obtained from nonlinear regression analysis of dose-response data for the compounds tested; these correspond to drug concentrations achieving halfmaximal inhibition of cell growth.

Parallel experiments based on the analysis of clonogenic survival following drug exposure for $3 \mathrm{~h}$ were also performed for some of the $\mathrm{Pt}$ derivatives, and the results 
Table 3. Molecular Descriptors and Statistical Information for the Best Regressions of the $\log \left(1 / \mathrm{IC}_{50}\right)$ on Human Ovarian Cancer Cells for the $16 \mathrm{Pt}^{\mathrm{II}}$ Complexes

\begin{tabular}{clcccr}
\hline model & \multicolumn{1}{c}{ variables } & $Q^{2}{ }_{\mathrm{LOO}} / Q^{2}{ }_{\mathrm{LMO}-50 \%}$ & $R^{2}$ & $s$ & \multicolumn{1}{c}{$F$} \\
\hline 1 & $\mathrm{CIC}_{2} I(3) e I(4) e I(2) p$ & $0.971 / 0.920$ & 0.988 & 0.111 & 221.7 \\
2 & $I(3) e I(4) e I(2) p$ & $0.950 / 0.914$ & 0.972 & 0.161 & 137.8 \\
3 & nR09 $I(2) p$ & $0.897 / 0.845$ & 0.932 & 0.241 & 88.5 \\
4 & $I(3) p$ & $0.680 / 0.637$ & 0.761 & 0.434 & 44.5 \\
\hline
\end{tabular}

were found to be fairly consistent with those obtained from the MTT assays (data not shown).

QSAR Analysis. QSAR analysis was performed using the procedure described in the Experimental Section. All of the reference regression models (four descriptors) performed well both in fitting and in prediction, as demonstrated by the results reported in Tables 3, 4, and 5. Despite the severe cross-validation procedure employed (50\% of the molecules were eliminated), the predictive capacity of the calculated regression models obtained proved highly satisfactory.

QSAR. Cytotoxic Activity of Pt ${ }^{\mathrm{II}}$ Complexes on A2780 Human Ovarian Cells. Statistical data for the best regression models of cytotoxic properties exerted on cultured human ovarian cancer cells for one, two, three, and four molecular descriptors are summarized in Table 3. The models were arranged in decreasing order of their dimensionality.

The best regression models are largely dominated by the presence of Moran indices of spatial autocorrelation $I(d) w^{41}$ differing either in the topological distance $d$ or in the physicochemical atomic properties $w$ under consideration (i.e., Sanderson atomic electronegativity $e$ and atomic polarizability $p$ ). The best regression model with four variables also contains the information descriptor $\mathrm{CIC}_{2}$, known as the complementary information content of second order index. ${ }^{42}$ The molecular descriptor nR09 appears in the best two-variable model and represents the number of nine-membered rings contained in the $\mathrm{Pt}^{\mathrm{II}}$ complexes. On the basis of the statistics shown in Table 3, we established the fourvariable model as the reference QSAR for the calculation of the $\log \left(1 / \mathrm{IC}_{50}\right)$. The complete regression equation for this reference model is as follows

$$
\begin{aligned}
\log \left(1 / \mathrm{IC}_{50}\right)(\mathrm{A} 2780)=- & 1.271+0.513 \mathrm{CIC}_{2}+3.821 I \\
& (3) e+2.858 I(4) e-4.747 I(2) p
\end{aligned}
$$

PCA was then performed on a data matrix containing the four molecular descriptors of the selected model in columns. The two PCs most highly correlated with the response were PC1 and PC4, accounting for $35.0 \%$ and $35.8 \%$, respectively, of the total variability of the observed response. As the PCs are mutually orthogonal, any combination of two or more PCs will explain the total fraction of the response variability given by the sum of the squared correlation coefficients between each $\mathrm{PC}$ and the response variable. Accordingly, the loading and score plots shown in Figure 3, obtained by combining $\mathrm{PC} 1$ and $\mathrm{PC} 4$, represent the relationships among the molecular descriptors and the structures of the $\mathrm{Pt}^{\mathrm{II}}$ complexes to which $70.8 \%$ of the observed variability of the response can be attributed.

Analysis of Figure 3 reveals that molecular descriptors such as $I(3) e$ and $I(4) e$ correlate precisely with the increase in the cytotoxic activity recorded for compounds

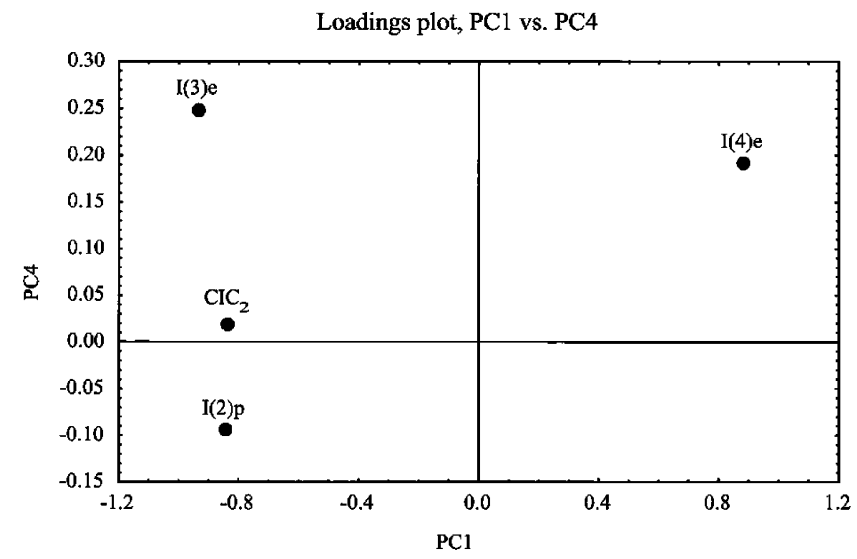

Scores plot, PC1 vs. PC4

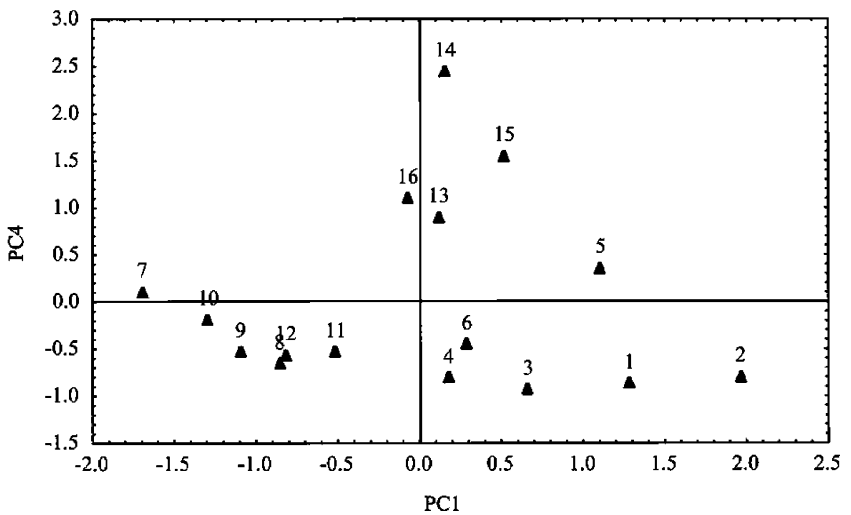

Figure 3. Loadings and score plots derived from PCA on the four molecular descriptors of the proposed QSAR model for $\log \left(1 / \mathrm{IC}_{50}\right)(\mathrm{A} 2780)$.

13-16 (PC4). Higher score values along the two PCs correspond to higher response values; hence, the most active compounds are those having positive score values on each PC. Compounds having negative score values on $\mathrm{PC} 1$ and $\mathrm{PC} 4$, instead, are less active ones (8-12). Furthermore, the loadings plot indicates that the relation of molecular descriptors such as $\mathrm{CIC}_{2}$ and $I(3) e$ to PC1 is just the opposite of that of $I(4) e$, even though their coefficients in the QSAR model have the same sign. This behavior can be ascribed to the well-known dependency of the MLR coefficients on the correlation structure of the $\mathrm{X}$ variables; with correlated variables, the role of each variable is impossible to assign on the basis of the MLR coefficients, and only their joint contribution to the response can be evaluated. The nature of the selected molecular descriptors suggests that the cytotoxic activity observed in human ovarian cells is mainly related to the electronic properties of the $\mathrm{Pt}^{\mathrm{II}}$ complexes. Moreover, analysis of the role of each descriptor in the QSAR model reveals that an increase in cytotoxic activity requires an increased fraction of electronegative atoms in the $\mathrm{Pt}$ II complexes, allowing optimization of the difference in electronegativity between atoms separated by three and four bonds. Noteworthy, evidence was clearly given that electronic effects do indeed play a role in modulating the antitumor activity of platinumbased drugs. ${ }^{43}$

QSAR. Cytotoxic Activity of Pt ${ }^{\mathrm{II}}$ Complexes on A2780Cp8 Cisplatin-Resistant Human Ovarian Cells. Statistical data for the best regression models of cytotoxic properties exerted on A2780Cp8 cells for 1,2 , 
Table 4. Molecular Descriptors and Statistical Information for the Best Regressions of the $\log \left(1 / \mathrm{IC}_{50}\right)$ on Cisplatin Resistant A2780 Human Ovarian Adenocarcinoma Cells (A2780Cp8) for the $16 \mathrm{Pt}^{\mathrm{II}}$ Complexes

\begin{tabular}{clcccc}
\hline model & \multicolumn{1}{c}{ variables } & $Q^{2}$ LOO $/ Q^{2}$ LMO-50\% & $R^{2}$ & $s$ & $F$ \\
\hline 1 & $\mathrm{TI}_{\mathrm{E}} \bar{I}_{\mathrm{B}} c(4) p$ BELe7 & $0.947 / 0.856$ & 0.973 & 0.144 & 97.9 \\
2 & $\mathrm{TI}_{\mathrm{E}} \bar{I}_{\mathrm{B}} \mathrm{c}(4) p$ & $0.912 / 0.847$ & 0.953 & 0.181 & 80.9 \\
3 & $c(1) v c(4) p$ & $0.825 / 0.759$ & 0.884 & 0.273 & 49.5 \\
4 & nR09 & $0.592 / 0.472$ & 0.663 & 0.448 & 27.5 \\
\hline
\end{tabular}

3, and 4 molecular descriptors are summarized in Table 4. The models were arranged in decreasing order of their dimensionality.

Because of the relevant correlation between the log$\left(1 / \mathrm{IC}_{50}\right)$ observed in $\mathrm{A} 2780$ cells and the cisplatin resistant counterparts A2780Cp8 $(r=0.917)$, the best regression models selected (listed in Tables 3 and 4) are based on quite similar molecular descriptors. The descriptors $c(1) v$ and $c(4) p$ are Geary indices of spatial autocorrelation calculated at the topological distances of 1 and 4, respectively, and weighted by van der Waals atomic volumes $v$ or atomic polarizabilities $p .{ }^{44}$ The definition of Geary indices, when applied to molecular graphs, is closely related to the definition of the Moran autocorrelation indices already listed in Table 3. Moreover, the descriptor nR09 appeared in some of the best regression models for both the responses. However, there are also some other descriptors listed in the best regression models for the $\mathrm{IC}_{50}$ values observed in the cisplatin-resistant cells. A brief description of the meaning of each descriptor is given below.

The molecular descriptor BELe7 is one of the BCUT descriptors family recommended when searching for chemical similarity/diversity in large databases ${ }^{45}$ and is based on an extension of the Burden approach. ${ }^{46}$ The BCUT descriptors are derived from hydrogen-included molecular graphs and are calculated from the Burden matrix, which is a modified adjacency matrix where the diagonal elements are atomic properties, whereas the off-diagonal elements corresponding to pairs of bonded atoms are the square roots of conventional bond orders; all of the other elements are set at 0.001. From this matrix, the BCUT descriptors are calculated as an ordered sequence of the highest and lowest eigenvalues: BELe7 is the lowest eigenvalue n.7 of the modified Burden matrix whose diagonal elements correspond to atomic Sanderson electronegativities.

The molecular descriptor $\bar{I}_{\mathrm{B}}$ is known as the lopping centric information index and is defined as the mean information content derived from the pruning partition of a molecular graph. ${ }^{47}$ This descriptor can be classified in the family of centric indices that were proposed to quantify the degree of compactness of molecules by distinguishing between molecular structures organized differently around their center.

The molecular descriptor $\mathrm{TI}_{\mathrm{E}}$ is known as the E-state topological parameter ${ }^{48}$ and is derived from the number of bonds and independent rings (cyclomatic number) in the molecule and the sum over all the adjacency atoms of the product between their E-state index values. ${ }^{49}$

On the basis of the data in Table 4, in this case, too, we established the four-variable model as the reference QSAR for calculation of the $\log \left(1 / \mathrm{IC}_{50}\right)$. The complete

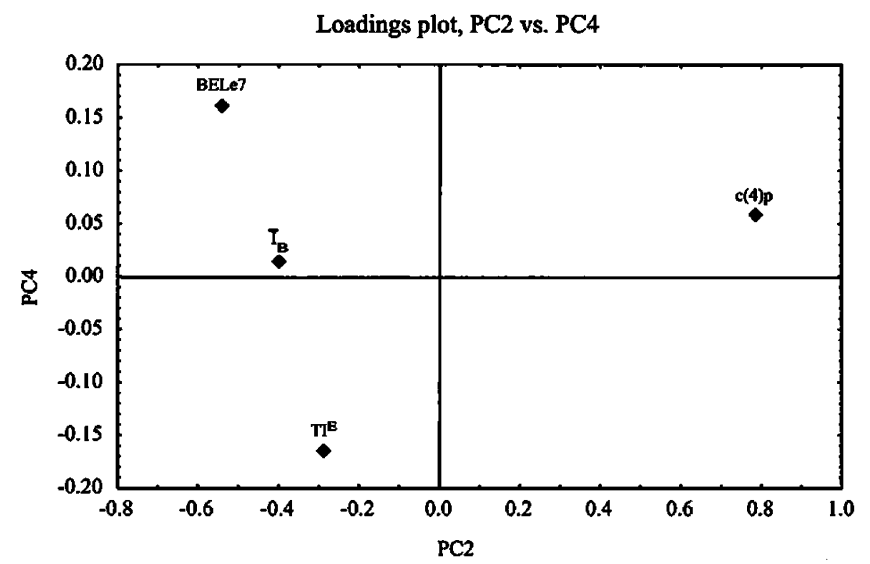

Scores plot, PC2 vs. PC4

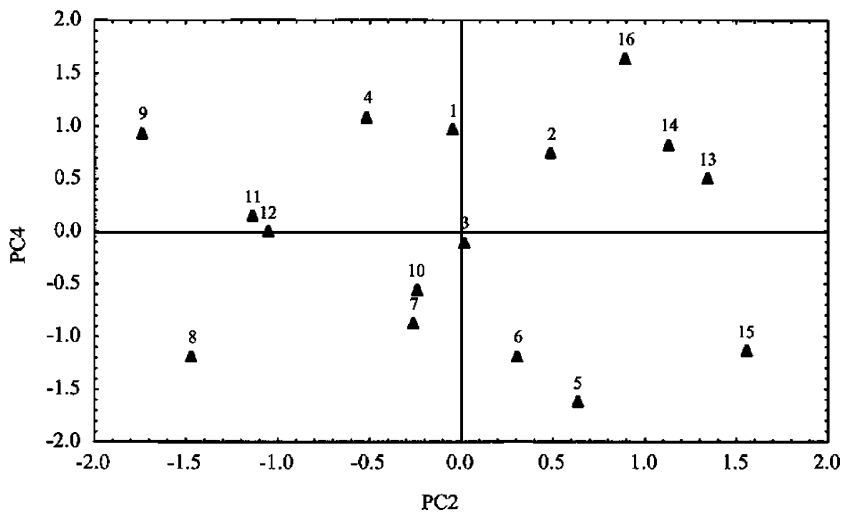

Figure 4. Loadings and score plots derived from PCA on the four molecular descriptors of the proposed QSAR model for $\log \left(1 / \mathrm{IC}_{50}\right)(\mathrm{A} 2780 \mathrm{Cp} 8)$.

regression equation for this reference model is as follows

$$
\begin{array}{r}
\log \left(1 / \mathrm{IC}_{50}\right)(\mathrm{A} 2780 \mathrm{Cp} 8)=0.154-0.030 \mathrm{TI}_{\mathrm{E}}- \\
2.537 \bar{I}_{\mathrm{B}}+1.872 c(4) p+1.116 \mathrm{BELe} 7
\end{array}
$$

To facilitate interpretation of the proposed model, PCA was performed on the matrix with the four molecular descriptors of the model, and the two PCs most highly correlated with the response were selected for further analysis.

The loading and score plots derived from PCA are shown in Figure 4. The plots were obtained by combining PC2 (88.1\% of response variance explained) and PC4 ( $8.4 \%$ of response variance explained), because they explain $96.5 \%$ of the total observed variability of $\log \left(1 / \mathrm{IC}_{50}\right)$.

The loadings plot shows the same distribution of molecular descriptors observed in Figure 3 even though different PCs were used to create the plot. The electronic properties of the $\mathrm{Pt}^{\mathrm{II}}$ complexes proved to be of great relevance in the determination of their activity in cisplatin-resistant cells. The loadings plot also shows that the effect of descriptor BELe7 is essentially negative although a contrary conclusion can be reached from the positive coefficient in the regression model; once again, the correlation among descriptors may lead to misinterpretation of the descriptor roles. As the two PCs are positively correlated with the response, $\mathrm{Pt}{ }^{\mathrm{II}}$ complexes having the highest positive score values on both PCs will be the most active ones $(\mathbf{1 3}, \mathbf{1 4}, \mathbf{1 6})$; instead, 
Table 5. Molecular Descriptors and Statistical Information for the Best Regressions of the Resistance Index RI for the $16 \mathrm{Pt}^{\mathrm{II}}$ Complexes

\begin{tabular}{clcccr}
\hline model & \multicolumn{1}{c}{ variables } & $Q^{2}{ }_{\text {LOO }} / Q^{2}{ }_{\text {LMO- } 50 \%}$ & $R^{2}$ & $s$ & \multicolumn{1}{c}{$F$} \\
\hline 1 & $I(8) p c(4) v$ BELe3 J & $0.963 / 0.844$ & 0.981 & 1.344 & 141.6 \\
2 & $I(8) p c(4) v$ BELe3 & $0.945 / 0.691$ & 0.973 & 1.539 & 142.7 \\
3 & $I(6) v$ BEHe5 & $0.849 / 0.725$ & 0.902 & 2.800 & 60.0 \\
4 & BELm3 & $0.785 / 0.578$ & 0.818 & 3.682 & 62.9 \\
\hline
\end{tabular}

$\mathrm{Pt}^{\mathrm{II}}$ complexes having the highest negative score values on both PCs will be the most inactive ones (8).

QSAR. Modeling the Dependency of the Resistance Index (RI) on the Basis of $\mathrm{Pt}^{\mathrm{II}}$ Complexes Structures. The resistance index was defined as the ratio between the $\mathrm{IC}_{50}$ value measured on cisplatin resistant cells (A2780Cp8) and the parental cells (A2780). $\mathrm{RI}$ values greater than 1 were calculated for all the $\mathrm{Pt}^{\mathrm{II}}$ complexes, proving the efficacy of the resistance mechanisms activated by the cells not only against cisplatin but also against all the other $\mathrm{Pt}^{\mathrm{II}}$ complexes used in this study. However, given that these mechanisms have a certain degree of molecular specificity, their efficacy can be expected to vary within a series of $\mathrm{Pt}^{\mathrm{II}}$ complexes according to their structural similarity to or diversity from cisplatin. We therefore extended our QSAR analyses to this response to discover the nature of the structural features that distinguish cisplatin resistance mechanisms.

The statistical data for the best regression models of RI for 1, 2, 3, and 4 molecular descriptors are summarized in Table 5 . The models were arranged in decreasing order of their dimensionality.

Again, the best regression models contain either Moran or Geary spatial autocorrelation indices and some BCUT descriptors, such as the lowest eigenvalues $\mathrm{n} .3$ weighted by atomic masses BELm3 or by Sanderson atomic electronegativities BELe3. Moreover, the model with two variables also contains the highest eigenvalues n.5 weighted by Sanderson atomic electronegativities.

The best regression model with four variables contains the molecular descriptor J, also known as the global topological charge index, which is one of the topological charge indices proposed for the evaluation of the charge transfer between pairs of atoms and, therefore, the global charge transfer in the molecule. ${ }^{50,51}$

On the basis of the statistics shown in Table 5, we once again proposed the model with four variables as the reference QSAR for the calculation of the resistance index. The complete regression equation for this reference model is as follows

$$
\begin{array}{r}
\mathrm{RI}=38.833+37.794 I(8) p-11.183 c(4) v- \\
16.087 \text { BELe3 }-7.7601 \mathrm{~J}
\end{array}
$$

The loadings and scores plots derived from PCA on the four molecular descriptors are shown in Figure 5. The plots were obtained by combining PC2 $(17.7 \%$ of response variance explained) and PC4 (58.2\% of response variance explained), and this combination explains $75.9 \%$ of the total observed variability of RI.

In this case, it is important to underline that PC2 is negatively correlated with the response, whereas the converse is true for PC4. Consequently, higher values of $c(4) v$ together with low values of $\mathrm{J}$ will minimize the response. However, PC4 is the most highly correlated

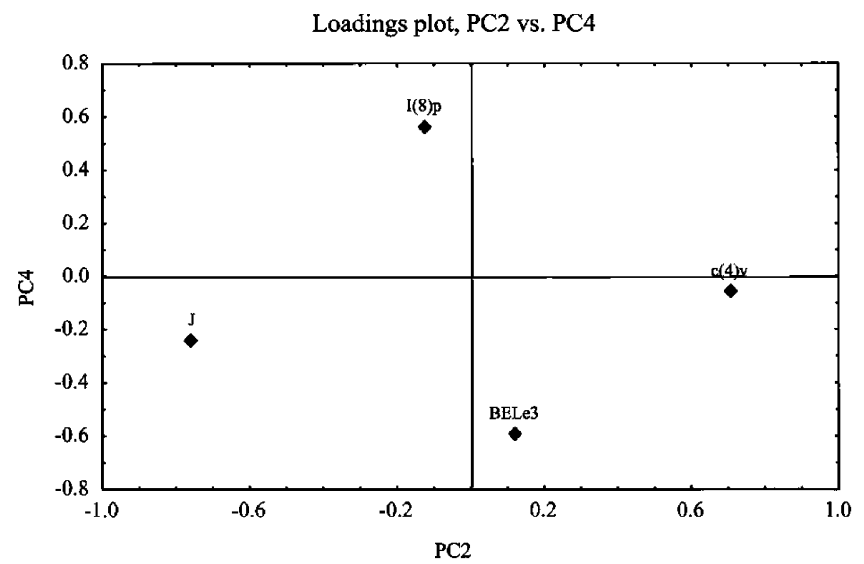

Scores plot, PC2 vs. PC4

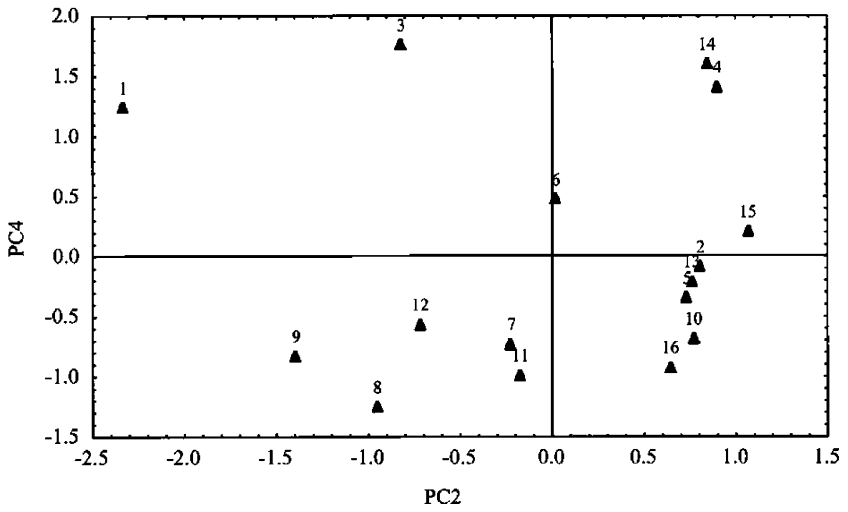

Figure 5. Loadings and score plots derived from PCA on the four molecular descriptors of the proposed QSAR model for the resistance index.

principal component with RI; hence, the molecular descriptors having high loadings along this axis will produce a larger effect on the response. In particular, high values of $I(8) p$ will increase the RI values, whereas high values of BELe3 will reduce the RI values. The scores plot clearly shows that cisplatin (1) is the most diverse compound in the series of $\mathrm{Pt}$ II complexes; indeed it is the compound with the highest RI, as expected given its induction of cellular resistance mechanisms.

From the data in Table 2, one can observe that complexes 13-16, which produce the electrophilic cis$\left[\mathrm{Pt}(\mathrm{DACH})\left(\mathrm{H}_{2} \mathrm{O}\right)_{2}\right]^{2+}$ species by aquation, are characterized both by high activity (low $\mathrm{IC}_{50}$ values) and by low cross resistance with cisplatin (low RI values).

\section{Conclusions}

Figure 6 shows the effects induced on the $\mathrm{IC}_{50}$ values for A2780 cells by varying the carrier ligands for any given leaving group. Figure 7 instead shows the effects induced by varying the leaving groups for any given carrier ligand.

In both cases, the trend observed for cytotoxicity evaluated in vitro confirms Cleare and Hoeschele's empirical rules as determined from in vivo experiments; the presence of $\mathrm{NH}_{3}$ or DACH as carrier groups yielded the highest cytotoxic effects, whereas chloride and oxalato proved to be the best leaving groups.

The QSAR approach provides simple regression models capable of predicting $\log \left(1 / \mathrm{IC}_{50}\right)$ of diamine-platinum(II) complexes. The four-variable model is able to 

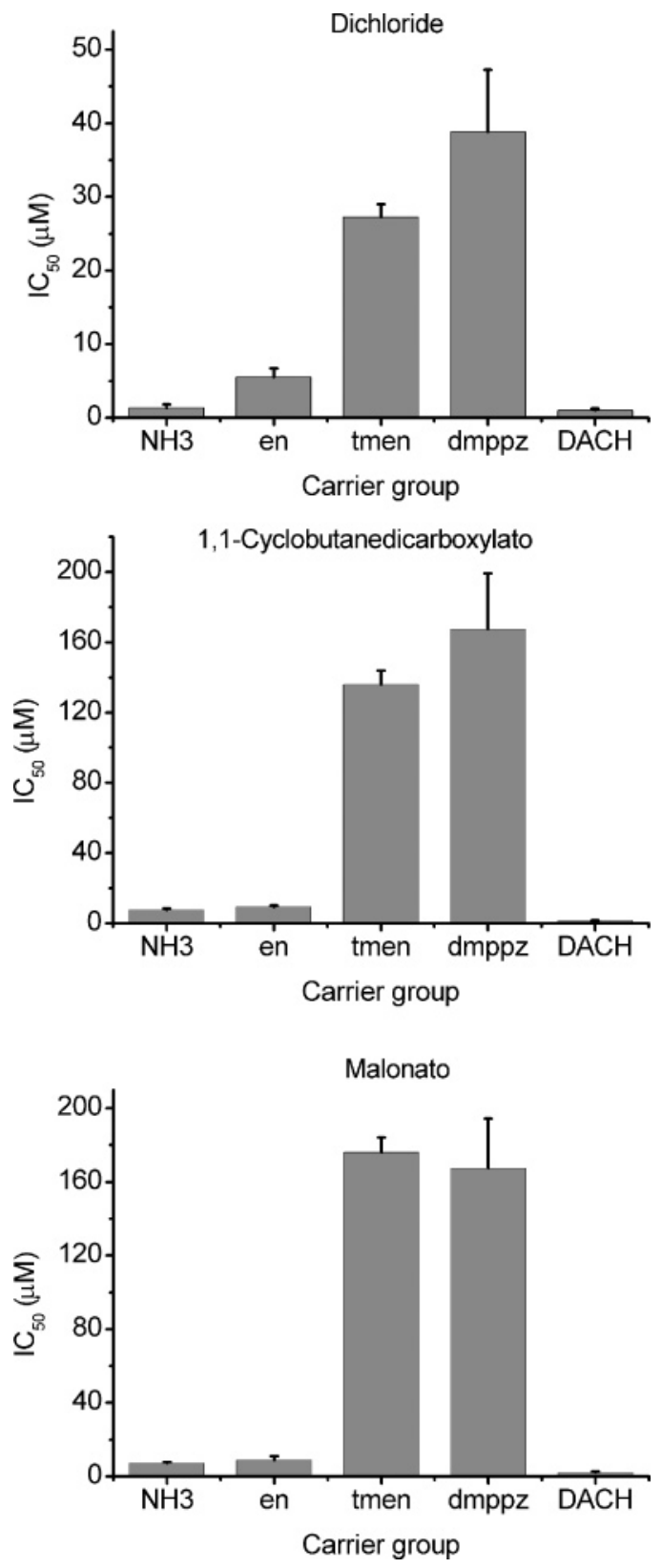

Figure 6. $\mathrm{IC}_{50}$ values for A2780: the effects obtained by varying the carrier ligands.

predict the gradual increase of $\mathrm{IC}_{50}$ (i.e., the decrease of cytotoxic activity) when passing from unsubstituted cis-dichlorideethylenediamineplatinum(II) $\left(\mathrm{IC}_{50}=5.55\right)$ to fully methylated cis-dichloride $\left(N, N, N^{\prime}, N^{\prime}\right.$-tetramethylethylenediamine)platinum(II) $\left(\mathrm{IC}_{50}=27.24\right)$. Interestingly, the methylation on the ethylendiamine chain is less detrimental than the methylation on terminal amine functionality for cytotoxicity (i.e., the cis-dichloride(2-methylethylenediamine)platinum(II) is predicted to have an $\mathrm{IC}_{50}$ value which is close to the unsubstituted congener $\left(\mathrm{IC}_{50}=4.75\right)$ ). The present QSAR model indicates the spacer should be linked to the ethylenediamine skeleton in order to obtain $\mathrm{Pt}^{\mathrm{II}}$ complex conjugated to biological vectors with a residual high cytotoxicity (Figure 1b). Unfortunately, this strategy is hindered from the minor chemical reactivity of $-\mathrm{CH}_{2}-$ with respect to $-\mathrm{NH}_{2}$ functionality. Work is in progress in

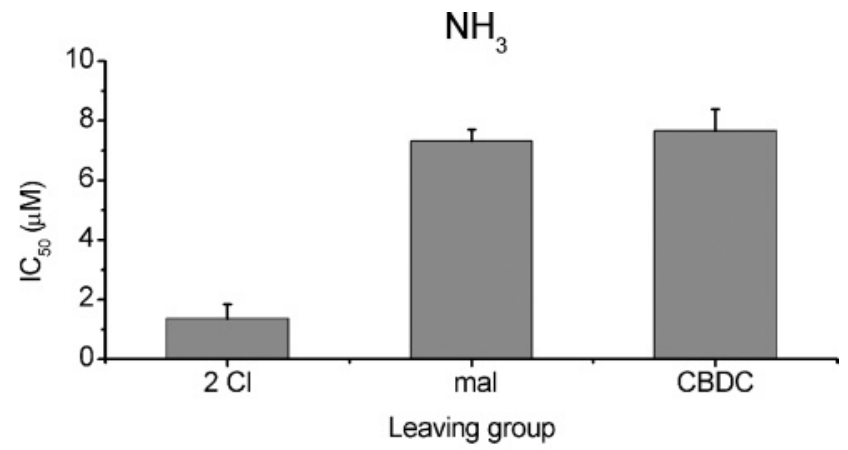

Tetramethylethylenediamine
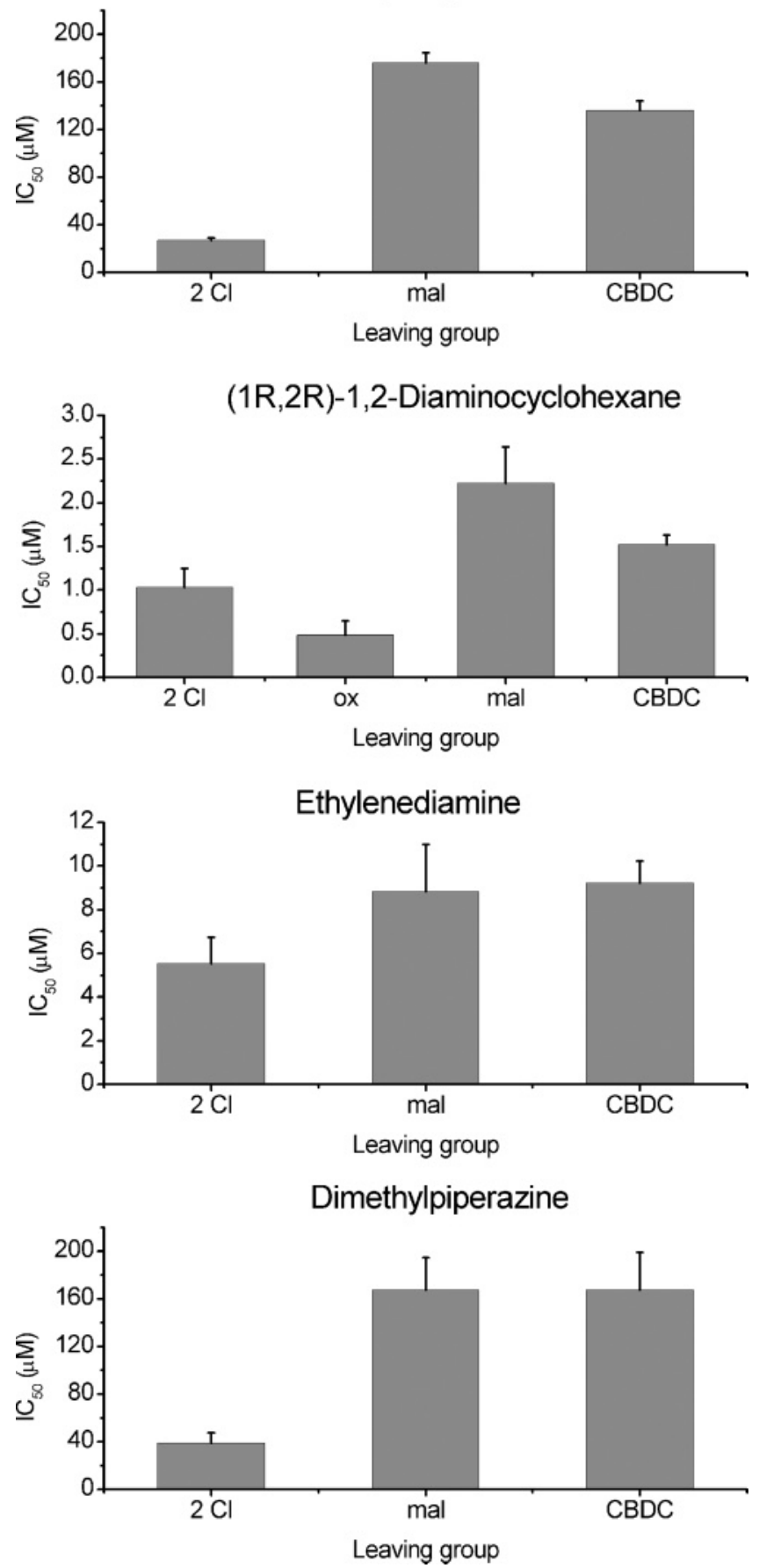

Figure 7. $\mathrm{IC}_{50}$ values for $\mathrm{A} 2780$ : the effects induced by varying the leaving groups.

our laboratories to synthesize and test such $\mathrm{Pt}^{\mathrm{II}}$ conjugate derivatives. 


\section{Experimental Section}

General Procedures. Platinum(II) complexes were synthesized according to standard procedures and were characterized by ESI mass spectrometry, ${ }^{52}$ HPLC, ${ }^{53}$ multinuclear NMR, and Raman spectroscopy. (Supporting Information)

Cytotoxicity Assays. A2780 human ovarian cancer cells and their cisplatin-resistant counterparts A2780Cp8 (so-called because of their ability to grow in medium containing $8 \mu \mathrm{M}$ cisplatin), developed by chronic exposure of the parent cisplatin-sensitive line to increasing concentrations of cisplatin, were obtained from Dr. R. Ozols (Fox Chase Cancer Center, Philadelphia, PA). ${ }^{20}$ A2780Cp8 cells differ from the parental cell line in a number of features that contribute to the resistant phenotype, including alterations in mismatch and nucleotide excision DNA repair systems and increased glutathione levels. ${ }^{20,40,54}$ Both parental and resistant cell lines were maintained in RPMI1640 medium (Sigma, Italy) supplemented with $10 \%$ fetal calf serum (Mascia Brunelli, Italy), $2 \mathrm{mM}$ L-glutamine, and $1 \%$ antibiotic mixture (Sigma, Italy) under standard culture conditions $\left(95 \% \quad \mathrm{O}_{2} / 5 \% \quad \mathrm{CO}_{2}\right.$ at $37{ }^{\circ} \mathrm{C}$ in a humidified atmosphere). Cell survival following exposure to the different platinum derivatives was evaluated using the MTT assay ([3-(4,5-dimethylthiazol-2-yl)-2,5-diphenyltetrazolium bromide]), which quantifies the number of surviving cells at a given time after exposure to cytotoxic drugs. ${ }^{55}$ Briefly, 1 $\times 10^{3}$ cells/well were plated onto 96 -well sterile plates in 100 $\mu \mathrm{L}$ of medium and allowed to grow for $24 \mathrm{~h}$. Platinum derivatives were dissolved in $\mathrm{H}_{2} \mathrm{O} / \mathrm{DMSO}$ and added to the wells in $100 \mu \mathrm{L} /$ well of complete culture medium. The final concentration range used was $0-500 \mu \mathrm{M}$; DMSO final concentration never exceeded $0.1 \%$. After $120 \mathrm{~h}, 50 \mu \mathrm{L}$ of MTT solution $(2 \mathrm{mg} / \mathrm{mL})$ was added to each well, and plates were incubated for $3 \mathrm{~h}$ at $37^{\circ} \mathrm{C}$. Cell viability was determined by measuring the absorbance at $570 \mathrm{~nm}$ using the universal microplate reader (Bio-Teck Instruments). All cytotoxicity experiments were performed three times in quadruplicate. The cytotoxic effects of the different platinum compounds were defined as the drug concentrations inhibiting tumor cell growth by $50 \%\left(\mathrm{IC}_{50}\right) . \mathrm{IC}_{50}$ values were calculated based on nonlinear regression analysis of dose-response data, performed using Calcusyn software (Biosoft, Cambridge, U.K.).

QSAR. The geometries of the 16 cis-Pt ${ }^{\mathrm{II}}$ complexes were fully optimized without symmetry constraints using the semiempirical quantum-mechanical PM3(tm) Hamiltonian as implemented in the SPARTAN ${ }^{56}$ molecular modeling software. All the minimized structures were confirmed as minima via harmonic frequency calculations (absence of imaginary frequencies). Furthermore, the three-dimensional structures obtained of the $\mathrm{Pt}^{\mathrm{II}}$ complexes were used as input for the DRAGON software, ${ }^{57}$ which was employed to numerically encode the topology and geometry of these molecules by theoretical molecular descriptors. To simplify the analysis, only the following sets of molecular descriptors were used for each structure (as listed in the Dragon software): constitutional descriptors, topological descriptors, walk and path counts descriptors, connectivity descriptors, information descriptors, 2-D autocorrelation descriptors, edge adjacency descriptors, BCUT descriptors, topological charge descriptors, and eigenvalue-based descriptors. ${ }^{58}$ The dimensionality of each descriptor set is shown in Table 6.

Use of all the descriptors led to a rather complex numerical description of each $\mathrm{Pt}^{\mathrm{II}}$ complex; the descriptors matrix was therefore filtered as follows to remove redundancy: (a) all constant descriptors were removed; (b) all descriptors differing from the others in only one value were excluded due to their low information content; (c) all descriptors having a correlation coefficient higher than 0.98 with another descriptor were removed. After the filter, only 197 molecular descriptors were retained for use in identifying suitable quantitative structureactivity relationships.

Cytotoxic activity was expressed as $\log \left(1 / \mathrm{IC}_{50}\right)$ to remove the strong deviation from normality of the original response variables, whereas the resistance index $\mathrm{RI}$ was used as is.

Correlation among all the biological responses under con-
Table 6. Dimensionality of the Set of Molecular Descriptors Used for the QSAR Study

\begin{tabular}{lc}
\hline \multicolumn{1}{c}{ descriptor set } & variables \\
\hline constitutional descriptors & 48 \\
topological descriptors & 119 \\
walk and path count descriptors & 47 \\
connectivity descriptors & 33 \\
information descriptors & 47 \\
2-D autocorrelation descriptors & 96 \\
edge adjacency descriptors & 107 \\
BCUT descriptors & 64 \\
topological charge descriptors & 21 \\
eigenvalue-based descriptors & 44 \\
total number of descriptors & 626 \\
\hline
\end{tabular}

sideration was estimated by multiple linear regression (MLR) based on the most predictive subset of molecular descriptors. The search for the best regression models was carried out using an exhaustive algorithm that examines all the possible descriptor combinations with dimensionality from 1 to 4 and retains only the five best correlations for each dimension. The best correlations were selected by using the "leave one out" cross-validation procedure maximizing the $Q^{2}$ LOO statistic. ${ }^{59}$ However, following the recommendations for QSAR modeling, ${ }^{60}$ each of the regression models retained was further validated using a "leave more out" procedure. This allowed analysis of the intrinsic stability of the models calculated when a higher level of perturbation, of up to $50 \%$ of the data available $\left(Q^{2}\right.$ LMO-50\%), was applied to the original data set.

Only the most stable regression model for each dimension examined was then selected and considered as a suitable quantitative structure-activity relationship. To select a reference QSAR model for each response, the standard error of estimates $(s)$ and the coefficient of determination $\left(R^{2}\right)$ were also calculated. All the calculations required in searching for the best regression models were performed using software provided by one of us (A.M.).

To interpret the selected QSAR models, a principal component analysis $(\mathrm{PCA})^{61}$ was performed on data matrices constructed from the molecular descriptors of the selected models calculated for the $16 \mathrm{Pt}^{\mathrm{II}}$ complexes. The two principal components (PCs) sharing the highest correlation coefficients with the response variable were then used to analyze either the relationships among the molecular descriptors by means of their loadings or the similarities among the $\mathrm{Pt}^{\mathrm{II}}$ complexes by means of their scores. PCA was performed on autoscaled data by using the STATISTICA software. ${ }^{62}$

Acknowledgment. This work was financially supported by MIUR (Roma), as part of the COFIN2001 project, and by C.I.R.C.M.S.B. (Bari). We are indebted to Johnson Matthey (Reading, U.K.) for a generous loan of $\mathrm{K}_{2}\left[\mathrm{PtCl}_{4}\right]$. This research was carried out within the framework of the European Cooperation COST D20 action (metal compounds in the treatment of cancer and viral diseases) and COST B16 action (multidrug resistance reversal). Thanks are due to Dr. L. McLean for her assistance in writing this manuscript.

Supporting Information Available: Synthesis and spectroscopic data for compounds 1-16; molecular descriptors, regression coefficients, and their standard errors for the best regression models; comparison among PM3(tm) and ab initio optimized geometric parameters for cisplatin. This material is available free of charge via the Internet at http:// pubs.acs.org.

\section{References}

(1) Ho, Y. P.; Au-Yeung, S. C. F.; To, K. K. W. Platinum-Based Anticancer Agents: Innovative Design Strategies and Biological Perspectives. Med. Res. Rev. 2003, 23, 633-655.

(2) Platinum-Based Drugs in Cancer Therapy; Kelland, L. R. Farrell, N. P., Eds.; Humana Press: Totowa, 2000. 
(3) Metallopharmaceuticals; Claarke, M. J., Sadler, P. J., Eds.; Springer-Verlag: Berlin, 1999; Vols. I and II.

(4) Cisplatin-Chemistry and Biochemistry of a Leading Anticancer Drug; Lippert, B., Ed.; Wiley-VCH: Weinheim, 1999.

(5) Metal Complexes in Cancer Chemotherapy; Keppler, B. K., Ed.; VCH: Weinheim, 1993.

(6) Basis for Cancer Management; Castagnetta, L., Nenci, I., Bradlow, H. L., Eds.; Annals of The New York Accademy of Sciences; New York Academy of Sciences: New York, 1996; Vol. 784.

(7) Receptor Activation by Antigens, Cytokines, Hormones, and Growth Factors; Naor, D., De Meyts, I., Feldman, M., Schleinger, J., Eds.; Annals of The New York Accademy of Sciences; New York Academy of Sciences: New York, 1995, Vol. 766.

(8) Hormones, A Practical Approach; Green, B., Leake, R. E., Eds.; IRL Press: Oxford, 1987

(9) Cytotxic Estrogens in Hormone Receptive Tumors; Raus, J., Martens, H., Leclercq, G., Eds.; Academic Press: London, 1980

(10) Cassino, C.; Gabano, E.; Ravera, M.; Cravotto, G.; Palmisano, G.; Vessières, A.; Jaouen, G.; Mundwiler, S.; Alberto, R.; Osella, D. Platinum(II) and Technetium(I) Complexes Anchored to Ethynylestradiol: A Way to Drug Targeting and Delivery. Inorg. Chim. Acta 2004, 357, 2157-2166.

(11) Greish, K.; Fang, J.; Inutsuka, T.; Nagamitsu, A.; Maeda, H. Macromolecular Therapeutics: Advantages and Prospects with Special Emphasis on Solid Tumour Targeting. Clin. Pharmacokinet. 2003, 42, 1089-1105.

(12) Maeda, H. The Enhanced Permeability and Retention (EPR) Effect in Tumor Vasculature: the Key Role of Tumor-selective Macromolecular Drug Targeting. Adv. Enzyme Regul. 2001, 41 189-207.

(13) Takakura, Y.; Mahato, R. I.; Hashida, M. Extravasation of Macromolecules. Adv. Drug Deliv. Rev. 1998, 34, 93-108.

(14) Jähde, E.; Rajewsky, M. F. Tumor-Selective Modification of Cellular Microenvironment in Vivo: Effect of Glucose Infusion on the $\mathrm{pH}$ in Normal and Malignant Rat Tissues. Cancer Res. 1982, 42, 1505-1512

(15) Tannock, I. F.; Rotin, D. Acid pH in Tumors and Its Potential for Therapeutic Exploitation. Cancer Res. 1989, 49, 4373-4384.

(16) Gerweck, L. E.; Seetharaman, K. Cellular pH Gradient in Tumor Versus Normal Tissue: Potential Exploitation for the Treatment of Cancer. Cancer Res. 1996, 56, 1194-1198.

(17) Wike-Hooley, J. L.; Haveman, J.; Reinhold H. S. The Relevance of Tumour $\mathrm{pH}$ to the Treatment of Malignant Disease. Radiother. Oncol. 1984, 2, 343-366.

(18) Cleare, M. J.; Hoeschele, J. D.; Studies on the Antitumor Activity of Group VIII Transition Metal Complexes. Part I. Platinum (II) Complexes. Bioinorg. Chem. 1973, 2, 187-210.

(19) Cleare, M. J. Transition Metal Complexes in Cancer Chemotherapy. Coord. Chem. Rev. 1974, 12, 349-405.

(20) Behrens, B. C.; Hamilton, T. C.; Masuda, H.; Grotzinger, K. R.; Whang-Peng, J.; Louie, K. G.; Knutsen, T.; McKoy, W. M.; Young, R. C.; Ozols, R. F. Characterization of a cis-Diamminedichloroplatinum(II)-Resistant Human Ovarian Cancer Cell-Line and Its Use in Evaluation of Platinum Analogues. Cancer Res. 1987, 47, 414-418.

(21) Yao, S. W.; Lopes, V. H. C.; Fernández, F. R.; García-Mera, X.; Morales, M.; Rodríguez-Borges, J. E.; Cordeiro, M. N. D. S. Synthesis and QSAR Study of the Anticancer Activity of Some Novel Indane Carbocyclic Nucleosides. Bioorg. Med. Chem. 2003, 11, 4999-5006.

(22) Wang, D. F.; Wiest, O.; Helquist, P.; Lan-Hargest, H. Y.; Wiech, N. L. QSAR Studies of PC-3 Cell Line Inhibition Activity of TSA and SAHA-like Hydroxamic Acids. Biorg. Med. Chem. Lett. 2004, 14, 707-711.

(23) Ren, S.; Wang, R.; Komatsu, K.; Bonaz-Krause, P.; Zyrianov, Y.; McKenna, C. E.; Csipke, C.; Tokes, Z. A.; Lien, E. J. Synthesis, Biological Evaluation, and Quantitative Structure-Activity Relationship Analysis of New Schiff Bases of Hydroxysemicarbazide as Potential Antitumor Agents. J. Med. Chem. 2002, $45,410-419$.

(24) Wanchana, S.; Yamashita, F.; Hashida, M. QSAR Analysis of the Inhibition of Recombinant CYP 3A4 Activity by Structurally Diverse Compounds Using a Genetic Algorithm-Combined Partial Least Squares Methodol. Pharm. Res. 2003, 20, 14011408.

(25) Dhara, S. C. A Rapid Method for the Synthesis of $c i s-\left[\mathrm{Pt}\left(\mathrm{NH}_{3}\right)_{2-}\right.$ $\mathrm{Cl}_{2}$ ]. Indian J. Chem. 1970, 8, 193-194.

(26) Harrison, R. C.; McAuliffe, C. A. An Efficient Route for the Preparation of Highly Soluble Platinum(II) Antitumour Agents. Inorg. Chim. Acta 1980, 46, L15-L16.

(27) Rochon, F. D.; Gruia, L. M. Synthesis and Characterization of $\mathrm{Pt}^{\mathrm{II}}$ Complexes with Amine and Carboxylato Ligands. Crystal Structure of (1,1-Cyclobutanedicarboxylato)di(ethylamine)platinum(II) $\cdot \mathrm{H}_{2} \mathrm{O}$. Inorg. Chim. Acta 2000, 306, 193-204.

(28) Hollis, L. S.; Doran, S. L.; Amundsen, A. R.; Stern, E. W. [Pt$\left(1,2\right.$-cyclohexanediamine)(ascorbato- $\left.\left.C^{2}, O^{5}\right)\right]$. Inorg. Synth. 1990 $27,283-286$.
(29) Kidani, Y.; Inagaki, K.; Iigo, M.; Hoshi, A.; Kuretani K. Antitumor Activity of 1,2-Diaminocyclohexaneplatinum Complexes Against Sarcoma-180 Ascites Form. J. Med. Chem. 1978, 21, $1315-1318$.

(30) Hoeschele J. D.; Rosenberg B.; Cleare M. J.; Van Camp L. L. Malonato Platinum Antitumor Compounds. U.S. Patent, 4,140,707, Feb 20, 1979.

(31) Pasini, A.; D’Alfonso, G.; Manzotti, C.; Moret, M.; Spinelli, S.; Valsecchi, M. Cytotoxic Diamine-Platinum(II) Complexes with Methylsulfinyl Carboxylates as the Leaving Groups. Synthesis, Characterization, and Reactivity toward Chloride Ions, 5'-GMP, and 9-Methylguanine. Inorg. Chem. 1994, 33, 4140-4148.

(32) Kerrison, S. J. S.; Sadler, P. J. ${ }^{195}$ Pt NMR Studies of Platinum(II) Dimethylsuphoxide Complexes. Inorg. Chim. Acta 1985, 104, 197-200.

(33) Tessier, C.; Rochon, F. D. Multinuclear NMR Study and Crystal Structures of Complexes of the Types cis- and trans-Pt(Ypy $)_{2} \mathrm{X}_{2}$, where $\mathrm{Ypy}=$ Pyridine Derivative and $\mathrm{X}=\mathrm{Cl}$ and I. Inorg. Chim. Acta 1999, 295, 25-38.

(34) Nakamoto, K. Infrared and Raman Spectra of Inorganic and Coordination Compounds, 5th ed; Wiley: New York, 1997; Part B, pp 63-67, 271.

(35) Barañska, H.; Kuduk-Jaworska, J.; Cacciari, S. Raman Study of Neutral Platinum-Imidazole Complexes. J. Raman Spectrosc. 1997, 28, 1-7.

(36) Barañska, H.; Kuduk-Jaworska, J.; Waszkiewicz, K. Vibrational Study of Cytotoxic bis(1-ethylimidazole)L(-)malatoplatinum(II) J. Mol. Struct. 2000, 550-551, 307-317.

(37) Nakamoto, K.; McCarthy, P. J.; Fujita, J.; Condrate, R. A.; Behnke, G. T. Infrared Studies of Ligand-Ligand Interaction in Dihalogenodiammineplatinum(II) Complexes. Inorg. Chem. 1965, 4, 36-43.

(38) Rochon, F. D.; Morneau, A. Pt-195 and $\mathrm{H}^{1}$-NMR Studies of Platinum(II) Complexes With Ethylenediamine Derivatives. Magn. Reson. Chem. 1991, 29, 120-126.

(39) Khan, S. R. A.; Guzman-Jimenez, I.; Whitmire, K. H.; Khokhar, A. R. Synthesis and Characterization of Piperidine Platinum(II) Complexes with Dicarboxylates: Crystal and Molecular Structure of cis-[Pt(piperidine) $\left.{ }_{2} \mathrm{Cl}_{2}\right] \cdot \mathrm{H}_{2} \mathrm{O}$. Polyhedron 2000, 19, 975-981.

(40) Colella, G.; Pennati, M.; Bearzatto, A.; Leone, R.; Colangelo, D.; Manzotti, C.; Daidone, M. G.; Zaffaroni, N. Activity of a Trinuclear Platinum Complex in Human Ovarian Cancer Cell Lines Sensitive and Resistant to Cisplatin: Cytotoxicity and Induction and Gene-Specific Repair of DNA Lesions. Br. J. Cancer 2001, $84,1387-1390$

(41) Moran, P. A. P. Notes on Continuous Stochastic Phenomena. Biometrika 1950, 37, 17-23.

(42) Magnuson V. R., Harris D. K., Basak S. C. Indices of Neighbourhood Symmetry. In Study in Physical and Theoretical Chemistry; King R. B., Ed.; Elsevier: Amsterdam, 1983; pp 178191.

(43) Boudreaux, E. A. Electronic Structure and Bonding of Platinum Anti-Tumour Drugs. In Metal-Based Anti-Tumour Drugs; Gielen, M. F., Ed.; Freund Publishing House Ltd.: London, 1988; pp $175-200$.

(44) Geary, R. C. The Contiguity Ratio and Statistical Mapping. Incorp. Statist. 1954, 5, 115-145.

(45) Pearlman, R. S.; Smith, K. M. Metric Validation and the Receptor-Relevant Subspace Concept. J. Chem. Inf. Comput. Sci. 1999, 39, 28-35.

(46) Burden, F. R. Molecular Identification Number for Substructure Searches. J. Chem. Inf. Comput. Sci. 1989, 29, 225-227.

(47) Balaban, A. T. Five New Topological Indices for the Branching of Tree-like Graphs. Theor. Chim. Acta 1979, 53, 355-375.

(48) Voelkel, A. Structural Descriptors in Organic-Chemistry-New Topological Parameter Based on Electrotopological State of Graph Vertexes. Comput. Chem. 1994, 18, 1-4.

(49) Kier, L. B.; Hall, L. H. Molecular Structure Description. The Electrotopological State. Academic Press: London, 1999.

(50) Galvez, J.; Garcìa, R.; Salabert, M. T.; Soler, R. Charge Indexes. New Topological Descriptors. J. Chem. Inf. Comput. Sci. 1994, $34,520-525$.

(51) Galvez, J.; Garcìa-Domenech, R.; De Julián-Ortiz, V.; Soler, R. Topological Approach to Drug Design. J. Chem. Inf. Comput. Sci. 1995, 35, 272-284.

(52) Bertani, R.; Seraglia, R.; Favretto, D.; Michelin, R. A.; Mozzon, M.; Mazzega Sbovata, S.; Sassi, A. Electrospray Mass Spectrometry of $\mathrm{Pt}{ }^{\mathrm{II}}$ Amidine Complexes of the Type cis- and trans- $\left[\mathrm{PtCl}_{2-}\right.$ $\left.\left\{\mathrm{NH}=\mathrm{C}(\mathrm{R}) \mathrm{NR}^{\prime} \mathrm{R}^{\prime \prime}\right\}_{2}\right]$ and trans- $\left[\mathrm{PtCl}_{2}(\mathrm{RCN})\left\{\mathrm{NH}=\mathrm{C}(\mathrm{R}) \mathrm{NR}^{\prime} \mathrm{R}^{\prime \prime}\right\}\right]$. Inorg. Chim. Acta 2003, 356, 357-364.

(53) Heudi, O.; Mercier-Joberd, S.; Cailleux, A.; Allain, P. Mechanisms of Reaction of L-Methionine with Carboplatin and Oxaliplatin in Different Media: A Comparison with Cisplatin. Biopharm. Drug Dispos. 1999, 20, 107-116. 
(54) Masuda, H.; Ozols, R. F.; Lai, G. M.; Fojo, A.; Rothenberg, M.; Hamilton, T. C. Increased DNA Repair as a Mechanism of Acquired Resistance to cis-Diaminedichloroplatinum(II) in $\mathrm{Hu}$ man Ovarian Cancer Cell Lines. Cancer Res. 1988, 48, 57135716.

(55) Alley, M. C.; Scudiero, D. A.; Monks, A.; Hursey, M. L.; Czerwinski, M. J.; Fine, D. L.; Abbott, B. J.; Mayo, J. G.; Shoemaker, R. H.; Boyd, M. R. Feasibility of Drug Screening with Panels of Human Tumor Cell Lines Using a Microculture Tetrazolium Assay. Cancer Res. 1988, 48, 589-601.

(56) SPARTAN '02; Wavefunction, Inc.: Irvine, CA, 2002.

(57) DRAGON Plus, release 4.0; Talete srl: Milan, Italy, 2003.
(58) Todeschini, R.; Consonni, V. Handbook of Molecular Descriptors; Wiley-VCH: Weinheim, 2000

(59) Shao, J. Linear-Model Selection by Cross-Validation. J. Am. Stat. Assoc. 1993, 88, 486-494.

(60) Wold, S.; Eriksson, L. In Chemometrics Methods in Molecular Design; van de Waterbeemd, H., Ed.; Wiley-VCH: Weinheim, 1995; pp 309-318.

(61) Jolliffe, I. T. Principal Component Analysis; Springer-Verlag: New York, 1986.

(62) STATISTICA for Windows, release 5.5; Statsoft, Inc.: Tulsa, OK 2000.

JM049508T 